\title{
Novel method for preventing cyclorotation in Ziemer Femto LDV Z8 femtosecond laser-assisted cataract surgery with Verion image-guided system
}

This article was published in the following Dove Medical Press journal: Clinical Ophthalmology

\author{
Hung-Yuan Lin ${ }^{1-3}$ \\ Ya-Jung Chuang ${ }^{4}$ \\ Pi-Jung Lin $^{5}$ \\ Yi-Ju $\mathrm{Ho}^{6}$
}

'Universal Eye Center, Zhong-Li, Taiwan, Republic of China;

${ }^{2}$ Department of Optometry, Central

Taiwan University of Science and

Technology, Taichung City, Taiwan,

Republic of China; ${ }^{3}$ Ophthalmology

Department, Shanghai Ruidong

Hospital, Shanghai, China; ${ }^{4}$ Universal

Eye Center, Long-Tan, Taiwan, Republic

of China; ${ }^{5}$ Universal Eye Center,

Taipei, Taiwan, Republic of China;

${ }^{6}$ Department of Ophthalmology,

Chang Gung Memorial Hospital,

Chiayi, Taiwan, Republic of China
Correspondence: Yi-Ju Ho

Department of Ophthalmology, Chang Gung Memorial Hospital, 6, Sec West,

Chai Pu Road, Puzi City, Chiayi, Taiwan, Republic of China

Tel +88653261000 ext 2115

Fax +886 53623002

Email freedomshield3800@gmail.com
Purpose: To investigate the feasibility of a new method involving the use of the Verion image-guided system in preventing cyclorotation during femtosecond laser-assisted cataract surgery (FLACS).

Patients: Our preliminary data included details of 24 consecutive patients. All patients underwent cataract surgery at Universal Eye Center, Zhong-Li, Taiwan, between December 2016 and January 2017.

Methods: We developed a technique to use the Verion image-guided system in FLACS and evaluated whether this new technique is compatible with Femto LDV Z8. The Verion imageguided system was used to prevent misalignments. The only additional step in this technique is using a marking tool to place ink on the corneal limbus (at 3 and 9 o'clock positions) guided by the Verion digital marker system. Remaining procedures could be performed using the touchscreen of Femto LDV Z8 to calibrate the horizontal reference axis.

Results: This study included 24 patients who underwent cataract surgery. The technique used could effectively neutralize misalignments at an average of $8.08^{\circ}$ and $2.66^{\circ}$ in clockwise and counterclockwise directions, respectively.

Conclusion: This technique combines the advantages of iris fingerprinting technology and mobile features of Femto LDV Z8, has fewer transfer steps, improves centration of the eyes, and, most importantly, can prevent misalignments through cyclotorsion or docking procedures. Furthermore, this method can improve the accuracy of arcuate incisions and toric intraocular lens alignment in astigmatism correction.

Keywords: cyclotorsion, astigmatism, alignment, fingerprint technology, toric

\section{Plain language summary}

Femtosecond laser-assisted cataract surgery (FLACS) featuring laser precision in astigmatic keratotomy and circular capsulotomy is now gaining popularity among cataract surgeons. Recently, a new modality with mobile function, Femto LDV Z8, was designed to provide a better laser profile and user-friendly operating system; however, these advantages cannot be realized until the misalignment and cyclotorsion are effectively eliminated. The conventional reference marking method is performed under a slit lamp and requires intraoperative patient transfer. Currently, an intraoperative image-guided system using iris fingerprint registration is used for managing astigmatism in cataract surgery. In this study, we developed a technique to use the Verion image-guided system in FLACS. This new technique is compatible with Femto LDV Z8. 


\section{Introduction}

Increasing numbers of ophthalmologists and patients are opting for femtosecond laser-assisted cataract surgery (FLACS). At present, commercially available FLACS systems include LenSx (Alcon Laboratories, Inc., Fort Worth, TX, USA), Catalys (Abbott Medical Optics, Santa Ana, CA, USA), Victus (Tecnolas/Bausch \& Lomb, Munich, Germany), LensAR (Topcon, Gamagori, Japan), and LDV Z8 (Ziemer Ophthalmic Systems AG, Port, Switzerland). In addition to lens fragmentation and the ability to create nearly circular capsulotomy, the benefits of FLACS include customizable and precise arcuate incisions, which improve the management of corneal astigmatism. ${ }^{1}$

One of the key factors to be addressed in astigmatism correction is misalignment, ${ }^{2}$ including ocular cyclotorsion, which is frequently encountered during refractive surgeries. ${ }^{3}$ Every one degree of misalignment can cause a loss of $\sim 3 \%$ of correction with femtosecond laser platforms or toric intraocular lenses (IOLs) in cataract surgeries. ${ }^{4-6}$ In addition, primary wound creation using clear corneal incision (CCI) can induce astigmatism. ${ }^{7}$ Deviation from target axis in toric IOLs implantation can be significantly decreased with Callisto Eye (Carl Zeiss Meditec AG, Jena, Germany) image-guided system $\left(3.6^{\circ} \pm 2.6^{\circ}\right)$ compared to that with manual marking $\left(5.5^{\circ} \pm 3.3^{\circ}\right) .{ }^{8}$ Our previously published data also demonstrated that horizontal slit beam marking resulted in a misalignment of $3.66^{\circ}$ compared with the Verion (Alcon Laboratories, Inc., Fort Worth, TX, USA) digital marking technique. ${ }^{9}$ Intraoperative imaging using the Verion image-guided system matched the preoperative image displaying the scleral vessels, limbal vessels, and iris morphology of the eyes, known as iris fingerprint registration. ${ }^{10}$ The software determined meridians with a limbal protractor projected over the view of a surgical microscope, guiding toric IOL alignments.

Many manual marking techniques, including pendular, tonometer, and bubble markers, were also reported in facilitating toric IOL implantation. ${ }^{11}$ These methods can prevent intraoperative cyclotorsion. However, subjective markers can result in potential rotational and vertical misalignments. ${ }^{12}$ Femtosecond laser-assisted astigmatic keratotomy (FSAK) with current modalities can be rapidly performed, with satisfactory efficiency of cylindrical error reduction. ${ }^{13}$ However, similar to traditional cataract surgeries, FLACS also requires precise alignment and a proper reference axis to prevent residual refractive error. Femto LDV Z8 is a femtosecond laser system used for corneal, corneal refractive, and cataract surgeries. However, this system cannot detect intraoperative cyclotorsion, horizontal misalignments, or vertical misalignments. Furthermore, primary and arcuate incisions require accurate axis determination to prevent residual or unexpected astigmatism postoperatively. Here, we propose a new method using the Verion image-guided system with Femto LDV Z8 for improved astigmatism correction during the FLACS procedure. To our knowledge, this is the first report of such a technique using Femto LDV Z8.

\section{Methods}

Our preliminary data included 35 consecutive eyes. All the patients underwent cataract surgery at Universal Eye Center, Zhong-Li, Taiwan, between December 2016 and January 2017. All the patients were informed regarding risks and benefits before cataract surgery, and they provided written informed consent in accordance with the institutional guidelines and the Declaration of Helsinki regarding human research. The present study was approved by the Institutional Review Board of Antai Tian-Sheng Memorial Hospital.

\section{Image acquisition and docking process}

Limbus registration was performed using the Verion imageguided system (with the patient seated in upright position). Initially, a preoperative high-resolution image was captured and then superimposed onto the surgical field under an operating microscope (Figure $1 \mathrm{~A})$. The two ends of $0^{\circ}-180^{\circ}$ horizontal axis were marked on the corneal limbus using a 27-gauge needle with ink guided by the Verion system (Figure 1B). Suction ring reference points at the temporal side (representing $0^{\circ}$ on the axis) and nasal side (representing $180^{\circ}$ on the axis) were aligned with ink marks. Furthermore, docking was achieved using a plastic-patient interface ring secured with suction. As soon as the suction vacuum approached 400 mbar, the suction ring was filled with a balanced salt solution. The handpiece, attached to an articulating arm of the laser system, was docked over the corneal apex.

\section{Novel method for meridian adjustment}

The Femto LDV Z8 image was acquired after docking; the two blue marks located $180^{\circ}$ apart at the limbus were clearly visualized (Figure 1C). Through the operator screen, the Femto LDV Z8 horizontal reference line was projected onto the cornea for planning CCI. The angular difference occurring between the reference and imaginary lines connecting the two blue marks was due to cyclotorsion. CCI was accomplished after manually aligning the two lines (Figure 1D). The aforementioned procedures were repeated for arcuate incision calibrations (Figure 1E and F). The angular difference between the reference axis and imaginary line was measured using ImageJ (National Institutes of Health, Bethesda, MD, USA). More specifically, a trained grader used the straight 

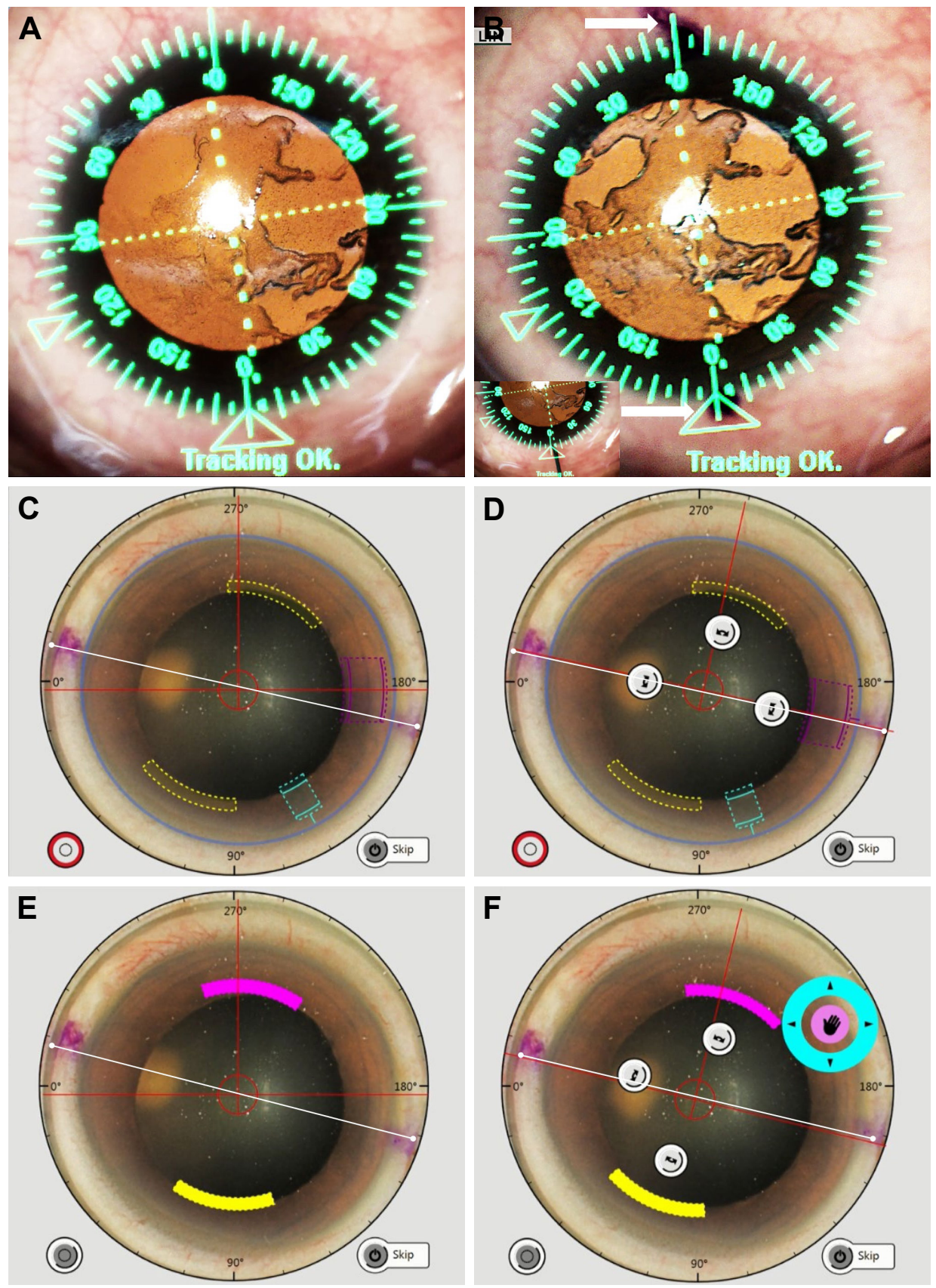

Figure I Stepwise illustration of applying image-guided system in FLACS.

Notes: (A) Iris registration with the Verion image-guided system. A limbal digital protractor is superimposed on the surgical field with real-time eye tracking. (B) Demonstration of blue marking placement. The blue marks (white arrow) were placed according to the Verion digital protractor $\left(0^{\circ}\right.$ and $180^{\circ}, 3$ and 9 o'clock positions) on the corneal limbus. The two ends of the reference axis were marked with a blue ink-colored 27-guage needle (inlet). (C) Demonstration of the horizontal reference axis using the Femto LDV Z8 after docking. Effect of cyclotorsion could now be measured (the angle between the white line and the red horizontal axis), and clear corneal incision calibration could therefore be performed. (D) Manual alignment of the reference axis in clear corneal incision using the Femto LDV Z8 was performed on the operator touchscreen. When the red reference axis (mark with white line with circular double ends) overlapped with the blue marking, the first calibration was considered complete. Clear corneal incisions were performed. (E) Demonstration of the horizontal reference axis using the Femto LDV Z8 for calibration of arcuate incisions. Effect of cyclotorsion could be measured based on the angle between the white line and the red horizontal axis. (F) Second time manual alignment of the reference axis for arcuate incisions planning using the Femto LDV Z8 was performed on the operator touchscreen. When the red reference axis overlapped with the blue marking, the second calibration was considered complete. Arcuate incisions could then be performed.

Abbreviation: FLACS, femtosecond laser-assisted cataract surgery.

line in Image J as horizontal reference marker and ensured its overlap with $0^{\circ}-180^{\circ}$ indicators of screenshot from LDV Z8. Then, the second line was deployed by connecting the blue markers we had previously drawn with guidance of Verion (also indicating $0^{\circ}-180^{\circ}$ before cyclorotation took place). Finally, we measured the angular difference between the reference marker and the second line. Thus, following the aforementioned simple steps, the Verion image-guided system 


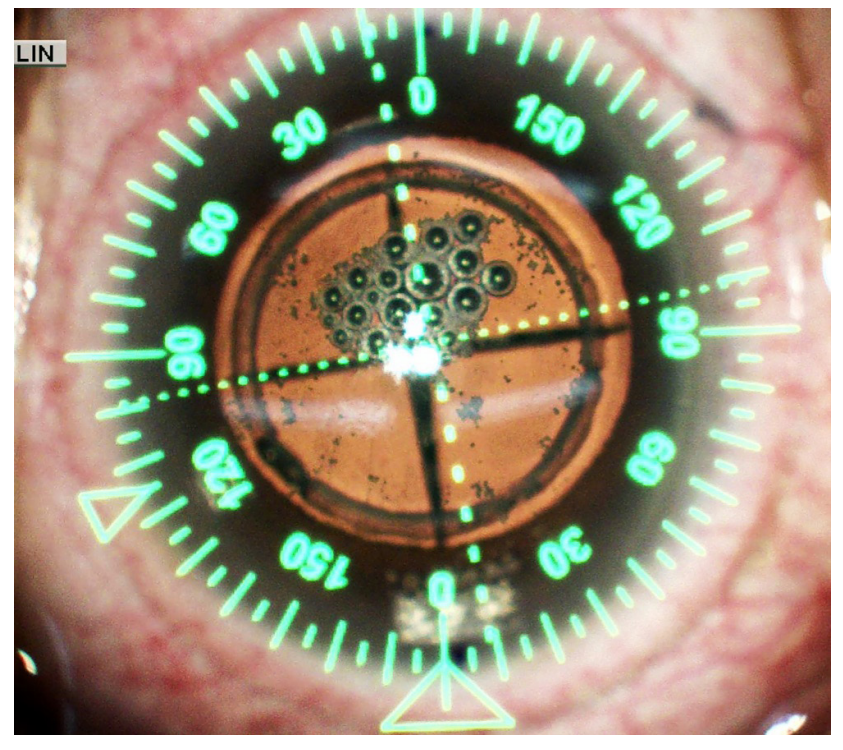

Figure 2 Demonstration of the alignments of clear corneal incision (performed at $0^{\circ}$ ) with Verion digital marks.

Notes: The incision was perfectly aligned with the Verion digital green protractor at $0^{\circ}$ and the corresponding blue marking. Good centration was noted after completion of all laser procedures.

was successfully integrated with the Ziemer Femto LDV Z8. The remaining procedures were performed according to the standard protocol. Treatment parameters were customized to accommodate each patient individually. Customized surgical procedures were performed through the precise placement of surgical incisions based on OCT images that identify ocular structures and automatically determine and display safety margins and suggested cut locations. Arcuate incisions were performed selectively based on surgeons' discretion. Following laser procedures, the suction ring was released, and the CCI and arcuate incisions could be visualized clearly (Figure 2). The remaining procedures were performed under the guidance of the Verion system.

\section{Results}

The results of our study demonstrated that using Verion as the reference meridian for arcuate incisions resulted in an average of $8.08^{\circ}$ and $2.66^{\circ}$ clockwise and counterclockwise misalignments, respectively. In cases where only one eye was involved, meridian adjustment was not necessary after docking. No adverse event occurred during the procedures throughout the study. However, extra time was still required before initiating femtosecond laser for operating touch screen and marking on surgical eyes.

\section{Discussion}

The primary factor determining efficacy in astigmatism correction is the accuracy of the alignment with respect to arcuate incision creation and toric IOL implantation. The primary wound can also produce unwanted surgically induced astigmatism due to intraoperative misalignment. The importance of cyclotorsion cannot be overemphasized.

The standard reference marking method is performed under a slit lamp with the patient in upright sitting position. The slit lamp is turned to the horizontal position with the light centered on the apex of the cornea. Subsequently, the horizontal meridian is marked by scratching the cornea with a 27-gauge needle and a marking pen under topical anesthesia, as described in our previous study. ${ }^{9}$ The final step is the intraoperative alignment of secondary modalities with reference markers. The manual marking techniques were well accepted among surgeons, yet it may not be ideal to incorporate to FLACS system.

Femto LDV Z8 is the latest development in refractive and cataract surgery, promising high flexibility, high mobility, and a favorable safety profile. ${ }^{14}$ This modality with its previous versions features great precision in performing corneal lamellar refractive surgery and cataract surgery. ${ }^{15}$ However, it cannot detect cyclotorsion occurring while shifting from an upright to a supine position; other factors could also contribute to intraoperative misalignment including suction forces from the liquid-patient interface ring and vertical compressive forces from the laser projector during docking. Here, we developed a new method that potentially aids surgeons in marking the reference axis using the Verion image-guided system and can avoid possible misalignment. Therefore, a horizontal marker can also be used to adjust centration due to lens tilting during suction docking in cases of small eyes or poorly cooperative patients.

In addition, the high mobility of Femto LDV Z8 enables patient procedures to be performed on the same surgical table as cataract surgeries. Incorporation of the Verion system can avoid additional steps of patient transfer needed in traditional marking, eliminating associated risks during surgery.

In a recent study conducted by Hummel et al, topographerbased iris registration was combined with a femtosecond laser platform (LENSAR) for assessing cyclotorsions. ${ }^{4}$ Cyclotorsions ranged from $0^{\circ}$ to $17^{\circ}$ with a mean absolute value of $\sim 5.81^{\circ}$. Although this can reduce the need for corneal marking and minimize residual cylindrical error, this method was exclusive to specific modalities due to the limited compatibility among different manufacturers and models. Furthermore, additional software, such as IntelliAxis (Topcon), may be required for transferring data from the topographer to LENSAR.

Newer technologies can now be applied to toric IOL implantation under digital image guidance. Current available 
modalities in addition to Verion include Callisto Eye (Carl Zeiss Meditec AG), iTrace (Tracey Technologies, Houston, TX, USA), and TrueGuide (TrueVision 3D Surgical, Inc., Santa Barbara, CA, USA). ${ }^{16}$

However, except for the LenSx system, other femtosecond laser platforms cannot be combined with the Verion image-guided system. Therefore, although Verion is accessible, traditional manual marking continues to be the most commonly used technique in FLACS. With this new technique, the current advantages of FLACS can be easily augmented in terms of precision of incision or FSAK and management of misalignment owing to positional cyclotorsion or mechanical decentration.

Because of new modalities featuring intraoperative measurement and all-in-one integration systems, preoperative examination has been simplified and the consequently reduced procedural redundancy may minimize measurement errors. Data transfer, workflow, and prevention of read-off errors were found to be better with the new proposed method. However, additional studies are needed to compare variations in results obtained using this new technique with those obtained using manual marking without an image-guided system.

\section{Acknowledgments}

With appreciation, this paper is edited by Beatrice Lin. No financial or material support was received from any sponsor or funder for this study.

\section{Disclosure}

The authors report no conflicts of interest in this work.

\section{References}

1. Venter J, Blumenfeld R, Schallhorn S, Pelouskova M. Non-penetrating femtosecond laser intrastromal astigmatic keratotomy in patients with mixed astigmatism after previous refractive surgery. $J$ Refract Surg. 2013;29(3):180-186.
2. Novis C. Astigmatism and toric intraocular lenses. Curr Opin Ophthalmol. 2000;11(1):47-50.

3. Chang J. Cyclotorsion during laser in situ keratomileusis. $J$ Cataract Refract Surg. 2008;34(10):1720-1726.

4. Hummel CD, Diakonis VF, Desai NR, Arana A, Weinstock RJ Cyclorotation during femtosecond laser-assisted cataract surgery measured using iris registration. J Cataract Refract Surg. 2017;43(7): 952-955.

5. Ma JJ, Tseng SS. Simple method for accurate alignment in toric phakic and aphakic intraocular lens implantation. $J$ Cataract Refract Surg. 2008;34(10):1631-1636.

6. Viestenz A, Seitz B, Langenbucher A. Evaluating the eye's rotational stability during standard photography: effect on determining the axial orientation of toric intraocular lenses. J Cataract Refract Surg. 2005;31(3):557-561.

7. Naeser K. Assessment and statistics of surgically induced astigmatism. Acta Ophthalmol. 2008;86(3):349.

8. Titiyal JS, Kaur M, Jose CP, Falera R, Kinkar A, Bageshwar LM. Comparative evaluation of toric intraocular lens alignment and visual quality with image-guided surgery and conventional three-step manual marking. Clin Ophthalmol. 2018;12:747-753.

9. Lin HY, Fang YT, Chuang YJ, et al. A comparison of three different corneal marking methods used to determine cyclotorsion in the horizontal meridian. Clin Ophthalmol. 2017;11:311-315.

10. Osher RH. Iris fingerprinting: new method for improving accuracy in toric lens orientation. J Cataract Refract Surg. 2010;36(2):351-352.

11. Woo YJ, Lee H, Kim HS, Kim EK, Seo KY, Kim TI. Comparison of 3 marking techniques in preoperative assessment of toric intraocular lenses using a wavefront aberrometer. $J$ Cataract Refract Surg. 2015;41(6):1232-1240.

12. Popp N, Hirnschall N, Maedel S, Findl O. Evaluation of 4 corneal astigmatic marking methods. J Cataract Refract Surg. 2012;38(12):2094-2099.

13. Viswanathan D, Kumar NL. Bilateral femtosecond laser-enabled intrastromal astigmatic keratotomy to correct high post-penetrating keratoplasty astigmatism. J Cataract Refract Surg. 2013;39(12): 1916-1920.

14. Riau AK, Liu YC, Lwin NC, et al. Comparative study of nJ- and $\mu \mathrm{J}$-energy level femtosecond lasers: evaluation of flap adhesion strength, stromal bed quality, and tissue responses. Invest Ophthalmol Vis Sci. 2014;55(5):3186-3194.

15. Reddy KP, Kandulla J, Auffarth GU. Effectiveness and safety of femtosecond laser-assisted lens fragmentation and anterior capsulotomy versus the manual technique in cataract surgery. $J$ Cataract Refract Surg. 2013;39(9):1297-1306.

16. Ventura BV, Wang L, Weikert MP, Robinson SB, Koch DD. Surgical management of astigmatism with toric intraocular lenses. Arq Bras Oftalmol. 2014;77(2):125-131.
Clinical Ophthalmology

\section{Publish your work in this journal}

Clinical Ophthalmology is an international, peer-reviewed journal covering all subspecialties within ophthalmology. Key topics include: Optometry; Visual science; Pharmacology and drug therapy in eye diseases; Basic Sciences; Primary and Secondary eye care; Patient Safety and Quality of Care Improvements. This journal is indexed on

Submit your manuscript here: http://www.dovepress.com/clinical-ophthalmology-journal

\section{Dovepress}

PubMed Central and CAS, and is the official journal of The Society of Clinical Ophthalmology (SCO). The manuscript management system is completely online and includes a very quick and fair peer-review system, which is all easy to use. Visit http://www.dovepress.com/ testimonials.php to read real quotes from published authors. 